\title{
HUBUNGAN ANTARA PRODUKTIVITAS PEKERJA GALANGAN DAN TEKNIK KERJA TERHADAP KINERJA GRAVING DOCK (STUDI KASUS DI PT. JANATA MARINA INDAH SEMARANG)
}

\author{
Suharto ${ }^{1}$ \\ ${ }^{1)}$ Jurusan Teknik Perkapalan, Fakultas Teknik, Universitas Diponegoro \\ Jl. Prof. Soedarto, Kampus Undip, Semarang, Indonesia 50275 email : \\ suharto2008@ymail.com
}

\begin{abstract}
Shipyard industry is one of the most important chain on the national shipping system. Notably to maintains the vessels condition in order to get adjustment of The Indonesia Classification Bureaustandard. Shipyard's productivity depends on the graving dock capacity, man productivity and work method. Empirical studies show that man competiveness and productivity and effective work method are primary factors which affects choice rate from shipping companies to a shipyard. The research goal was to analyzed the effect of man productivity and work method toward graving dock performance in PT. Janata Marina Indah Semarang. Multiple linear regression used as a method in this research. Methodology use basic is difficulty to identify relating directly from man productivity and work method toward graving dock performance. The sampling method using purposive random sampling with 35 respondents who have long experience in the graving dock works. The result of regression analysis is: $\quad Y=-0,357+0,256 X 1+0,249 X 2$. The result shows that two factors both man productivity and work method, are have significant effect toward graving dock performance.
\end{abstract}

\section{Keywords : Man Productivity, Work Method, Graving Dock Performance}

\begin{abstract}
Abstrak : Industri galangan kapal merupakan salah satu rantai penting dalam sistem perkapalan nasional. Khususnya dalam menjaga kondisi kapal agar tetap layak jalan sesuai standar Biro Klasifikasi Indonesia. Kualitas reparasi galangan tergantung kapasitas graving dock, produktivitas pekerja dan teknik kerja. Studi empiris menunjukkan bahwa pekerja yang kompeten dan produktif dan teknik kerja yang efektif merupakan faktor utama yang mempengaruhi tingkat pemilihan perusahaan perkapalan pada suatu galangan. Tujuan penelitian ini adalah untuk menganalisis pengaruh produktivitas pekerja dan teknik kerja terhadap kinerja graving dock di PT. Janata Marina Indah Semarang. Metode yang digunakan adalah analisis regresi berganda dengan program SPSS 17. Dasar penggunaan metodologi tersebut karena faktor tenaga kerja dan teknik kerja sulit dihitung tingkat efeknya secara langsung terhadap kinerja graving dock. Penentuan sampel menggunakan purposive randome sampling dengan 35 responden yang berkompeten dalam pekerjaan di graving dock. Hasil analisis regresi yaitu : $Y=-0,357+0,303 X 1+0,339 X 2$. Hasil temuan menunjukkan bahwa faktor produktivitas pekerja dan teknik kerja mempunyai pengaruh yang positif dan signifikan terhadap kinerja graving dock.
\end{abstract}

Kata Kunci : Produktivitas Pekerja, Teknik Kerja, Kinerja Graving Dock. 
Pertumbuhan ekonomi Indonesia selama satu dekade terakhir telah meningkatkan kapasitas dan laju distribusi barang baik melalui darat, laut maupun udara. Perusahaan transportasi, terutama kapal laut, menjadi pilihan masyarakat untuk mendistribusikan produk melalui berbagai pilihan jasa yang disediakan (Break Bulk, Bag Cargo, Unitized, Curah Kering, Curah Cair, Peti Kemas atau Tanpa Kemasan, Kapal Niaga, Kapal Bukan Niaga, Docking atau Emergency). Kapal laut dipilih karena merupakan alat transportasi yang paling efektif yang bisa mengangkut muatan dalam kuantitas yang sangat banyak sehingga biayanya menjadi sangat murah. Banyaknya kapal baru yang hadir di Indonesia membuat pertumbuhan industri galangan kapal meningkat. Biro Klasifikasi Indonesia (2003) mengestimasi pertumbuhan usaha galangan di Indonesia rata-rata sebesar 16 persen pertahun.

Industri galangan kapal mempunyai karakter penguasaan teknologi yang masif, akumulasi kapital yang besar dan resiko yang tinggi (Shin \& Shon, 2000). Industri galangan merupakan industri strategis, terlebih bagi negara kelautan (coastal nation) (Lamb, et al., 2001; Pires \& Lamb, 2008). Galangan berperan dalam meminimalisir efek cuaca laut terhadap performa kapal. Kecepatan kapal akan berkurang akibat pengaruh cuaca di laut lepas sebesar 25\% (Caridis, 2001). Stabilisasi kapal melalui reparasi sangat penting bagi kelangsungan kapal untuk mengembalikannya ke keadaan semula (Farhum, 2010). Pertumbuhan jumlah kapal membuat galangan kapal bekerja lebih keras karena semakin banyak kapal yang direparasi. Aslesen and Svein (2012) menyatakan proyek galangan kapal mempunyai 3 fungsi utama yaitu mendesain, perincian teknik (detailed engineering) dan konstruksi. Reparasi kapal adalah melalui graving dock. Dock adalah sarana yang dilengkapi peralatan dan perlengkapan agar badan kapal dapat duduk diatasnya dalam keadaan kering tidak tercelup ke air (Soegiono dkk, 1984). Graving dock biasanya berbentuk ruangan (compartment) dimana kapal dapat mengapung kemudian bertumpu pada balokbalok pada saat perbaikan setelah air dipompa keluar (Huda, 2006). Ukuran dock disesuaikan dengan besar kapal. Ukuran kapal yang semakin besar membuat galangan kapal berusaha membuat graving dock dengan kapasitas yang lebih besar.

Salah satu galangan kapal terbesar di Jawa Tengah yang mempunyai kapasitas graving dock yang sangat memadai adalah PT. Janata Marina Indah (JMI) yang terletak di Pelabuhan Tanjung Emas Semarang. Pada saat ini, kapasitas dock PT. JMI Unit II Semarang sebesar 18.500 DWT dapat mereparasi kapal barang, feri, kapal tanker dan kapal perang.

Untuk dapat merealisasikan proyek dengan sukses, sebuah galangan dituntut bisa mempunyai kinerja yang prima dalam kualitas, waktu dan kriteria biaya (König, et $a l$, 2007). Produktivitas yang tinggi dan hasil kapal yang berkualitas merupakan reputasi utama bagi industri galangan (Gebhardt \& 
Jarvis, 2003). Biasanya produktivitas galangan diukur melalui indikator Compensated Gross Tonnage/CGT (Bruce, 2006; Bertram, 2003). First Marine International (2005) menyatakan kelemahan CGT adalah tidak menganalisis keterkaitan sumber daya perusahaan sebagai variabel produktivitas galangan secara langsung. Penelitian ini berusaha menganalisis secara kuantitatif korelasi sumber daya galangan yaitu pekerja dan penerapan teknik kerja sebagai faktor penting dalam kinerja graving dock.

Kinerja sebuah galangan tergantung pada pendayagunaan, efisiensi dan sistematisasi sumber daya yang dimiliki (Lee, Dong Kun et al, 2014; Shin \& Sohn, 2000). Sumber daya pekerja yang produktif dan metode kerja yang efektif berpengaruh terhadap keberhasilan sebuah proyek konstruksi. Moyst \& Das (2005) menunjukkan bahwa faktor pekerja dapat mempunyai pengaruh terhadap kinerja galangan. Koenig and Baba (2003) menunjukkan bahwa lingkungan kerja yang memadai berperan dalam peningkatan kinerja galangan. Pekerja yang mempunyai produktivitas yang tinggi dan penerapan metode yang cocok akan membuat reparasi kapal berlangsung dengan lebih cepat. Dengan kapasitas graving dock 18.500 DWT, setiap tahun PT. JMI Unit II dapat menyelesaikan rata-rata 63 buah kapal. PT. JMI masih mempunyai peluang besar untuk meningkatkan jumlah kapal yang direparasi dengan peningkatan produktivitas para pekerja dan perbaikan metode kerja yang digunakan. Roland et al (2004) menyatakan aplikasi praktek industrial dan teknik yang efektif merupakan faktor penting dalam peningkatan keunggulan kompetitif galangan kapal di Eropa secara cepat dan signifikan. Lamb, et al (2006), Moyst \& Das (2005) menyatakan bahwa perbaikan proses kerja akan meningkatkan kinerja galangan.

Dari uraian tersebut, maka dipandang penting untuk mengetahui sejauh mana produktivitas pekerja dan metode kerja yang digunakan dapat berguna dalam meningkatkan kualitas reparasi kapal. Urgensinya adalah untuk komparasi perhitungan kinerja aktual dengan target kinerja (Lamb \& Hellesoy, 2002; Lamb, et al, 2006).

Kalkulasi produktivitas galangan total merupakan sebuah kesulitan, bahkan untuk galangan besar dunia sekalipun (Krishnan, 2012; Lamb, T., et al. , 2001). Penelitian ini menganalisis kinerja graving dock secara parsial melalui produktivitas pekerja dan teknik kerja. Tujuannya untuk menganalisis produktivitas pekerja dan teknik kerja terhadap kinerja PT. JMI dalam usaha melayani reparasi kapal melalui graving dock.

\section{METODOLOGI}

Penelitian ini merupakan studi kasus (case study) pada graving dock PT. JMI Semarang. Studi kasus adalah penelitian mengenai suatu subyek penelitian yang berkenaan dengan suatu fase spesifik atau khas dari keseluruhan personalitas (Hasan, 
2002). Penelitian ini merupakan studi korelasional untuk mengetahui hubungan (relationship) antara faktor produktivitas tenaga kerja, dan metode kerja terhadap faktor kinerja graving dock.

Guna mendapatkan sampel yang representatif, penelitian ini menggunakan metode sampling acak bertujuan (purposive random sampling). Kuesioner digunakan untuk memperoleh data langsung dari sumber asli/responden (data primer). Dengan kriteria pendidikan minimal Sekolah Kejuruan dan pengalaman minimal 5 tahun, maka diperoleh responden sebanyak 35 orang yang terdiri dari Kabag lambung, dock, peralatan, safety, out fitting, listrik, umum, mesin, quality kontrol, kepala proyek, bagian konstruksi, dock master, pengawas/ supervisor, juru selam, bagian kebersihan dan bagian pemeliharaan.

Sebelum dilanjutkan pada tahap analisis terdapat dua syarat penting yang berlaku pada sebuah angket, yaitu keharusan sebuah angket untuk valid dan reliabel (Ghozali, 2009). Validitas merupakan indikator bahwa item pertanyaan angket mampu untuk mengungkapkan sesuatu yang akan diukur. Indikatornya adalah nilai $r$ hitung positif dan $r$ hitung $>r$ tabel. Pengukuran validitas menggunakan rumus :

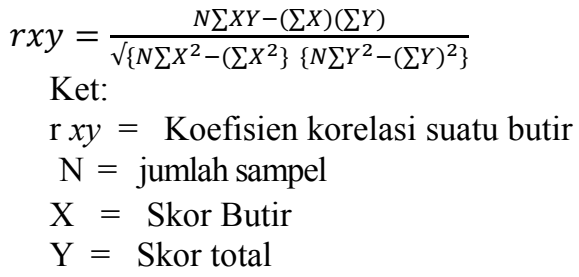

Ket:

$r x y=$ Koefisien korelasi suatu butir

$\mathrm{N}=$ jumlah sampel

$\mathrm{X}=$ Skor Butir

$\mathrm{Y}=$ Skor total

Rumus untuk mengkonversi $t$ hitung $\geq t$ tabel menjadi $r$ hasil $>r$ tabel menggunakan rumus :

$$
\begin{gathered}
r=\sqrt{\frac{t^{2}}{t^{2}+(n-2)}} \\
\text { Ket }: \mathrm{n}=\text { jumlah variabel }
\end{gathered}
$$

Sedangkan reliabilitas (kehandalan) adalah konsistensi atau kestabilan jawaban responden dari waktu ke waktu. Dasar penilaian adalah $\alpha$ harus positif, dan $\alpha>r$ tabel. Berdasarkan taraf keberartian $(\alpha)=$ $5 \%$, uji 1 sisi (1-tiled), dan derajat kebebasan $($ degree of freedom $/$ df $)=$ jumlah data $-2=35$ $-2=33$ didapat nilai $r$ tabel $=0,28260$. Pengujian reliabilitas menggunakan rumus Cronbach Alpha sebagai berikut (Amrozi, 2007) :

$\alpha=\left(\frac{k}{k-1}\right)\left(1-\frac{\sum S_{1}^{2}}{S_{1}^{2}}\right)$

Ket :

$\mathrm{k} \quad=$ jumlah item

$\sum S_{1}^{2}=$ jumlah varians skor total

$S_{1}^{2}=$ varians responden untuk item ke-i

Untuk menganalisis kualitas data digunakan uji asumsi klasik. Uji ini dilakukan karena dalam model regresi menjadi tidak efisien jika asumsi klasik tidak dipenuhi. Asumsi-asumsi klasik yang harus dipenuhi yaitu :

a. Uji multikolonieritas, dengan indikator nilai cut off nilai Tolerance $<0,10$ atau sama dengan nilai $\mathrm{VIF}>1,0$.

b. Uji heteroskedastistas dengan deteksi statistik melalui uji Glejser. 
c. Uji normalitas dengan identifikasi distribusi normal data dengan uji Kolmogorov-Smirnov.

Sedangkan pengujian besarnya efek produktivitas tenaga kerja dan metode kerja dan signifikansinya terhadap kinerja graving dock menggunakan analisis regresi berganda.

Persamaan garis regresi yang digunakan adalah :

$$
\begin{aligned}
\mathrm{Y} 1=\mathrm{a}+ & \mathrm{b}_{1} \mathrm{X}_{1}+\mathrm{b}_{2} \mathrm{X}_{2}+\mathrm{b}_{\mathrm{n}} \mathrm{X}_{\mathrm{n}}+\mathrm{e} \\
\text { Di mana : } & \\
\mathrm{Y} 1= & \text { Kinerja Graving dock (variabel } \\
& \text { terikat } 1) \\
\mathrm{a}= & \text { Konstanta (intercept) } \\
\mathrm{b}_{\mathrm{n}}= & \text { Koefisien variabel independen } \\
& \text { (slope) } \\
\mathrm{X}_{\mathrm{n}}= & \text { Faktor-faktor lain yang } \\
& \text { mempengaruhi kinerja graving } \\
& \text { dock }
\end{aligned}
$$

Analisis berganda dilakukan dalam dua tahap pembuktian hipotesis :

\section{a. Uji Serentak (Uji F)}

Uji $\mathrm{F}$ digunakan untuk menilai apakah faktor produktivitas tenaga kerja dan teknik kerja secara serentak mempunyai pengaruh signifikan terhadap kinerja graving dock. Kriteria pengujian hipotesis yang diterima (Ha) adalah nilai $F$ hitung lebih besar dari nilai $F$ tabel $(=3,2759)$ (Sugiyono,2005). Walpole dan Myers (dalam Amrozi, 2007) cara menghitung nilai statistic $F$ dengan rumus berikut :

$$
\begin{aligned}
& F=\frac{\left(R^{2} / k\right)}{\left|\left(1-R^{2}\right) /(n-k-1)\right|} \\
& \text { Di mana : } \\
& \mathrm{R}^{2}=\text { koefisien determinasi } \\
& \mathrm{N}=\text { jumlah responden } \\
& \mathrm{k}=\text { jumlah variabel bebas }
\end{aligned}
$$

Koefisien determinasi dihitung dengan persamaan sebagai berikut :

$\mathrm{R}^{2}=\underline{\text { Jumlah Kuadrat (JK) regresi }}$

$$
\Sigma \mathrm{yi}^{2}
$$

\section{b. Uji Pengaruh Parsial (Uji $t$ )}

Pengujian secara parsial merupakan salah satu bentuk pengujian pengaruh dari masing-masing variabel dengan asumsi bahwa variabel lain adalah konstan. Menghitung nilai statistik $t$ dengan rumus berikut (Sugiyono,2006) :

$$
\begin{aligned}
& t=\frac{X-\mu_{0}}{\frac{s}{\sqrt{n}}} \\
& \text { Di mana : } \\
& \mathrm{t}=\text { nilai } \mathrm{t} \text { yang dihitung (t hitung) } \\
& \bar{X}=\text { Rata-rata } \mathrm{X} \\
& \mu_{O}=\text { nilai yang dihipotesiskan } \\
& \mathrm{s}=\text { simpangan baku } \\
& \mathrm{n}=\text { Jumlah sampel }
\end{aligned}
$$

Indikator yang digunakan sebagai basis penerimaan hipotesis adalah jika menghasilkan nilai $t$ hitung lebih besar dari $\mathrm{t}$ tabel $(=1,6924)$. $T$ hitung berada pada batasan penerimaan pada kurva distribusi normal dibawah ini :

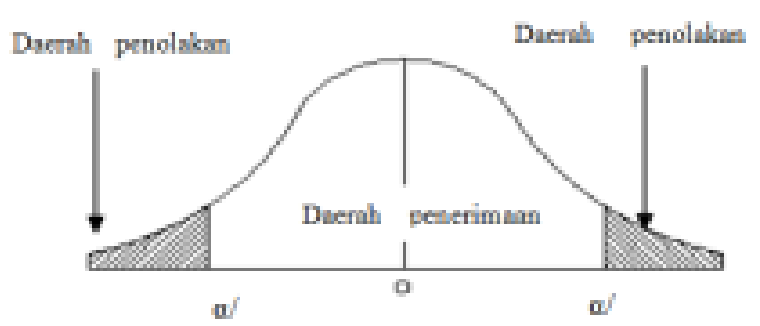

Gambar 1. Kurva Distribusi Normal (Sugiyono, 2006) 


\section{HASIL DAN PEMBAHASAN}

\section{Gambaran Umum Lokasi Penelitian}

PT. Janata Marina Indah Unit II dibangun di lingkungan Pelabuhan Tanjung Emas, kelurahan Bandarharjo, Kecamatan Semarang Utara. Lahan PT. JMI menempati areal seluas 8,1 Ha. Disamping untuk lokasi graving dock, sebagian lahannya untuk pembangunan kapal baru di building birth dan kolam apung (floating quay) untuk kegiatan reparasi kapal di atas air.

\section{Kondisi Topografi}

Ketinggian wilayah Kecamatan Semarang utara rata-rata 0.75 meter di atas permukaan laut dengan topografi sebagian besar terdiri dari dataran dan daerah pantai. Kondisi permukaan datar atau daerah dataran terletak di bagian utara kecamatan. Lokasi Graving dock PT. Janata Marina Indah unit II terletak pada kondisi topografi berupa dataran yang datar dan merupakan tanah reklamasi pantai.

\section{Kondisi Lokasi Eksisting}

Lokasi Graving dock tersebut berada pada kilometer $1+100$ di jalur pantura/jalan arteri Yos Sudarso. Lokasi graving dock PT. Janata Marina Indah unit II dibatasi oleh :

- Sebelah Barat : lahan milik Pelindo III/Pemda dan terminal Elpiji OPSICO.

- Sebelah Timur : pelabuhan rakyat.

- Sebelah Selatan : pemukiman dan jalan pantura/Jalan Arteri Yos Sudarso
- Sebelah Utara dermaga Opsico dan semen Tiga Roda.

\section{Aspek Teknis}

Sebagai salah satu galangan terbesar, PT. JMI banyak mengerjakan jasa reparasi kapal dari berbagai jenis dan ukuran. Data dari tahun 2006 hingga 2010, graving dock PT JMI menyelesaikan target reparasi kapal sebagai berikut :

Tabel 1. Jumlah Kapal dan Waktu Reparasi di PT. Janata Marina Indah (Tahun 2006-2010)

\begin{tabular}{rcc}
\hline Tahun & $\begin{array}{c}\text { Jumlah } \\
\text { kapal masuk }\end{array}$ & $\begin{array}{c}\text { Rata-rata } \\
\text { waktu reparasi } \\
\text { (hari) }\end{array}$ \\
\hline 2006 & 52 & 7.02 \\
\hline 2007 & 54 & 6.76 \\
\hline 2008 & 66 & 5.53 \\
\hline 2009 & 79 & 4.62 \\
\hline 2010 & 63 & 5.79 \\
\hline $\begin{array}{c}\text { Rata- } \\
\text { rata }\end{array}$ & 63 & 5.94 \\
\hline
\end{tabular}

Sumber : Marketing PT. JMI, 2006-2010

Berdasarkan data tersebut terdapat kecenderungan bahwa produktivitas kinerja graving dock mengalami kenaikan yang fluktuatif tiap tahunnya. Jumlah kapal yang masuk graving dock yang berhasil diselesaikan berkisar rata-rata 63 buah pertahun. Sedangkan waktu penyelesaian rata-rata reparasi graving dock adalah 5,94 hari/kapal.

\section{Aspek Finansial}

Dari segi finansial, banyaknya jumlah kapal yang diselesaikan oleh graving dock PT JMI berpengaruh terhadap pendapatan perusahaan. 
Tabel 2. Aspek Finansial Graving Dock

\begin{tabular}{cc}
\hline Tahun & $\begin{array}{c}\text { Pendapatan Reparasi Kapal } \\
(\mathrm{Rp})\end{array}$ \\
\hline 2006 & $42,699,021,850$ \\
\hline 2007 & $48,421,911,709$ \\
\hline 2008 & $77,104,830,751$ \\
\hline 2009 & $86,084,405,357$ \\
\hline 2010 & $76,288,552,105$ \\
\hline $\begin{array}{r}\text { Rata- } \\
\text { rata }\end{array}$ & $66,119,744,354$ \\
\hline
\end{tabular}

Sumber : Marketing PT. JMI, 2006-2010

Berbanding lurus dengan jumlah kapal yang masuk, pendapatan perusahaan dan dana total pemeliharaan kapal di graving dock PT. JMI juga mengalami kenaikan fluktuatif. Sepanjang 2006 hingga 2010, jumlah pendapatan rata-rata PT. JMI terkait dengan reparasi melalui graving dock adalah sebesar Rp. 66,119 juta. Hal ini menguatkan asumsi bahwa produktivitas pekerja dan metode kerja yang digunakan akan berpengaruh secara langsung terhadap keuangan perusahaan. Artinya peningkatan produktivitas pekerja dan metode merupakan keharusan bagi perusahaan galangan. Karena graving dock merupakan keunggulan komparatif bagi perusahaan galangan, mengingat minimnya resiko dan umur pemakaian yang tahan lama (Soejitno,1999).

\section{Analisis Data}

\section{Analisis Statistik}

Analisis statistik yang digunakan dalam penelitian ini meliputi kualitas perolehan data dan kualitas internal data. Basis perhitungannya adalah korelasi dan komparasi nilai konstruk. Hubungan variabel pada model dicari dengan menganalisis adanya efek dan signifikansi antar variabel.

\section{Uji Validitas}

Penghitungan uji validitas menggunakan ukuran perhitungan korelasi antar masingmasing skor item pertanyaan dari tiap variabel dengan total skor faktor. Kuesioner dikatakan valid jika semua nilai $r$ hitung di atas nilai $r$ tabel (Ghozali, 2007). Nilai $r$ tabel adalah sebesar 0,3061 yang didapatkan pada tingkat signifikansi 0,05 dan $\mathrm{df}=33$. Pengujian menunjukkan bahwa semua item butir mempunyai nilai nilai $r$ hitung (Corrected Item-Total Correlation) diatas 0,3061 sehingga semua butir dinyatakan valid.

\section{Reliabilitas}

Untuk mengukur konsistensi internal dari suatu konstruk atau variabel dapat digunakan uji reliabilitas. Kriteria yang digunakan adalah membandingkan nilai correlated item-total correlation dengan nilai $r$ tabelnya. Nunally (Ghozali, 2007) memberikan batasan penerimaan reliabilitas nilai Cronbach Alpha> $60 \%$.

Berdasarkan pengujian diperoleh nilai Cronbach's Alpha pada faktor produktivitas tenaga kerja dan metode kerja sebesar 0,804 dan 0,797. Nilai Cronbach Alpha faktor kinerja graving dock sebesar 0,615 . Semua nilai faktor lebih besar daripada 0,60 sehingga semua konstruk penelitian ini adalah reliabel. 


\section{Analisis Regresi}

Tabel 3. Hasil SPSS Regresi Berganda

\begin{tabular}{lcccc}
\hline Model & $\begin{array}{c}\text { Standardized } \\
\text { Coefficients } \\
\text { (B) }\end{array}$ & $\begin{array}{l}\text { Std. } \\
\text { Error }\end{array}$ & t & Sig. \\
\hline (Constant) & -.357 & .532 & -1.844 & \\
\hline $\begin{array}{l}\text { Produktvitas } \\
\text { tenaga_kerja }\end{array}$ & .256 & .048 & 6.316 & 0.00 \\
\hline Teknik Kerja & .249 & .067 & 5.058 & 0.00 \\
\hline
\end{tabular}

Sumber : Pengolahan data SPSS

Berdasarkan tabel tersebut, maka persamaan regresi yang dihasilkan dalam penelitian ini adalah sebagai berikut :

$$
\mathrm{Y}=-0,357+0,256 \mathrm{X} 1+0,249 \mathrm{X} 2
$$

Hasil tersebut menyatakan kinerja graving dock akan mengalami kenaikan jika produktivitas tenaga kerja dan teknik kerja mengalami peningkatan dan perbaikan. Kesesuaian arah antara kinerja graving dock dan peningkatan produktivitas tenaga kerja dan metode kerja dapat dilihat pada arah koefisien variabel yang positif (+). Sebaliknya, kinerja graving dock juga akan turun jika produktivitas tenaga kerja dan metode kerja mengalami penurunan yang dapat dilihat pada arah konstanta yang negatif (-) 0,357 .

Koefisien determinasi $\left(\mathrm{R}^{2}\right)$ yang dihasilkan dalam penelitian ini sebesar 0,356. Koefisien determinasi menggambarkan seberapa besar pengaruh variabel independen terhadap variabel dependen. Hal ini berarti 35,6\% persen kinerja graving dock dapat dijelaskan oleh variabel Produktivitas Tenaga Kerja dan Metode Kerja. Sedangkan sisanya sebesar 64,4\% (100\% - 35,6\%) dari kinerja graving dock dijelaskan oleh variabel lain selain kedua variabel independen tersebut.

\section{a. Variabel Produktivitas Pekerja}

Berdasarkan hasil pengolahan SPSS tersebut, dapat diketahui bahwa nilai koefisien regresi produktivitas tenaga kerja adalah sebesar 0,303. Tingkat signifikansi variabel adalah sebesar $0,000(<0,05)$ dengan $\alpha 95 \%$, maka variabel produktivitas tenaga kerja dapat dijadikan sebagai prediktor variabel kinerja graving dock. Tanda koefisien yang positif $(+)$ sebesar 0,256 menunjukkan bahwa pengaruh produktivitas tenaga kerja terhadap kinerja graving dock kapal adalah positif atau berbanding lurus, artinya semakin baik produktivitas tenaga kerja, maka kinerja graving dock akan semakin baik.

Hasil ini menunjukkan bahwa dalam kondisi ceteris paribus, penambahan waktu kerja yang sebanding dengan satu hari akan meningkatkan kinerja sebesar 25,6\% menjadi $125,6 \%$. Sebagai gambaran, PT. Janata Marina Indah menyelesaikan reparasi sebuah kapal dalam waktu kerja rata-rata sebesar 5,96 hari. Jika ditambahi dengan waktu lembur setara sehari (24 jam) maka kapal akan selesai dalam jangka waktu 4,75 hari (5,96 dibagi 125,6\%). Dengan semakin rendahnya waktu pengerjaan reparasi tiap kapal, maka jumlah kapal yang dapat diselesaikan setiap tahun akan naik menjadi rata-rata 76 kapal dari kondisi sekarang dengan rata-rata jumlah kapal yang 
diselesaikan 63 buah kapal/tahun. Hal ini mengindikasikan bahwa peningkatan kinerja reparasi kapal melalui graving dock akan sangat tergantung pada besarnya produktivitas para pekerja.

\section{b. Variabel Teknik Kerja}

Koefisien regresi variabel metode kerja adalah sebesar 0,249. Tingkat signifikansi variabel metode kerja adalah sebesar 0,000 (< $0,05)$ dengan $\alpha 95 \%$. Tanda koefisien yang positif $(+)$ sebesar 0,249 menunjukkan bahwa pengaruh metode kerja terhadap kinerja graving dock adalah positif atau berbanding lurus, artinya semakin baik metode kerja, maka kinerja graving dock akan semakin baik.

Hal ini membuktikan bahwa metode kerja yang canggih diperlukan untuk mengantisipasi berbagai keadaan sulit yang mungkin muncul. Dalam proyek konstruksi, adakalanya metode terobosan diperlukan untuk menyelesaikan pekerjaan di lapangan. Khususnya pada saat menghadapi kendalakendala yang diakibatkan oleh kondisi lapangan yang tidak sesuai dengan dugaan sebelumnya. Untuk itu, penerapan metode pelaksanaan konstruksi yang sesuai kondisi lapangan, akan sangat membantu dalam penyelesaian proyek konstruksi bersangkutan. Penggunaan metode yang tepat, praktis, cepat, dan aman, sangat membantu dalam penyelesaian pekerjaan pada suatu proyek konstruksi.

Studi empiris dari House menunjukkan bahwa metode kerja yang

Volume 1, No. 2, Juli 2015 meliputi kapasitas graving dock, kesesuaian dock dengan kapal, pelayanan insiden atau kejadian yang sulit, reputasi, waktu pelaksanaan, efisiensi fasilitas docking, kemudahan administrasi, bengkel kerja yang memadai, sistem gudang persediaan dan tenaga kerja yang memadai dan berkompeten akan mempengaruhi tingkat pemilihan konsumen reparasi kapal. Reksohadiprodjo dan Gitosudarmo (2000) menjelaskan bahwa organisasi seperti perusahaan jasa graving dock harus mencari dan menerapkan suatu metode kerja yang paling ekonomis dan selalu mencari metode baru yang lebih baik.

\section{Uji Asumsi Klasik}

\section{a. Pengujian Multikoliniearitas}

Indikator multikolinearitas adalah nilai Tolerance dan Variance Inflation Faktor (VIF). Kedua ukuran ini menunjukkan setiap variabel bebas manakah yang dijelaskan oleh variabel bebas lainnya. Pengukuran multikolonieraitas adalah dengan melihat nilai cutoff yang umum dipakai adalah nilai tolerance 0,10 atau sama dengan nilai VIF di atas 1. Hasil penghitungan menunjukkan produktivitas tenaga kerja mempunyai nilai VIF 2,196 dan tolerance 0,455. Faktor metode kerja mempunyai nilai $V I F 3,242$ dan tolerance 0,308 . Hasil tersebut menegaskan bahwa semua faktor yang digunakan tidak menunjukkan adanya gejala multikoliniearitas dalam model regresi.

\section{b. Pengujian Heteroskedastisitas}

Model regresi yang baik adalah yang mempunyai perbedaan deviasi standar nilai 
variabel dependen pada setiap variabel independen. Adanya heteroskedatisitas menimbulkan varians koefisien regresi menjadi minimum dan confidence interval deviasi melebar sehingga uji signifikansi menjadi tidak valid.

Hasil pengujian statistik heteroskedastisitas melalui uji Glejser menegaskan tingkat signifikansi sebesar 0,951 (variabel produktivitas tenaga kerja) ; 0,60 (teknik kerja) ; 0,118 (kinerja) atau di atas tingkat signifikansi 0,05 sebagai tolak ukur penerimaan asumsi uji heteroskedastisitas. Berdasarkan hasil ini maka dapat disimpulkan bahwa residual varians model adalah homogen atau tidak terjadi heteroskedastisitas.

\section{c. Uji Normalitas}

Model regresi yang baik adalah memiliki distribusi data normal atau mendekati normal. Uji statistik normalitas dengan uji Kolmogorov-Smirnov Z (KS test) menunjukkan nilai signifikansi sebesar 0,562 yang lebih besar dari 0,05 maka dapat disimpulkan bahwa data residual terdistribusi secara normal. Data yang normal adalah data yang mempunyai nilai signifikansi lebih besar daripada 0,05 pada tingkat kepercayaan $95 \%$.

\section{Pembuktian Hipotesis}

\section{Uji Secara Serentak (Uji F)}

Dari hasil perhitungan statistik diperoleh nilai $F$ sebesar 217,755 dengan tingkat signifikansi 0,000 . Nilai $F$ hitung $(217,555)$ lebih besar dari nilai $F$ tabel $(3,2759)$ sebagai dasar penerimaan uji serentak. Hal ini berarti bahwa variabel independen (produktivitas pekerja dan metode kerja) secara bersamasama mempunyai pengaruh signifikan pada peningkatan kinerja graving dock.

\section{Uji Secara Parsial (Uji $t$ )}

Berdasarkan hasil pengujian diperoleh untuk variabel produktivitas tenaga kerja diperoleh nilai $\mathrm{t}$ hitung $=6,316$ dengan tingkat signifikansi 0,000 . Dengan menggunakan batas signifikansi 0,05, maka diperoleh nilai $\mathrm{t}$ tabel dengan $\mathrm{df}=33$ adalah sebesar 1,6924. Dengan demikian diperoleh $\mathrm{t}$ hitung $(6,316)>\mathrm{t}$ tabel $(1,6924)$ sehingga hipotesis (Ha) diterima. Dapat disimpulkan bahwa hipotesis yang menyatakan bahwa produktivitas tenaga kerja berpengaruh positif dan signifikan terhadap kinerja graving dock adalah terbukti. Hasil temuan serupa dari Koenig and Baba (2003); Lamb and Aasmund (2002) menyatakan bahwa tenaga kerja yang berkompetensi tinggi berperan dalam peningkatan produkvitas galangan. Shin, J. G., \& Sohn, S. J. (2000) menyatakan peningkatan produktivitas pekerja adalah mutlak diperlukan dalam industri galangan kapal agar tetap kompetitif.

Berdasarkan hasil pengujian diperoleh untuk variabel metode Kerja diperoleh nilai $t$ hitung $=5,058$ dengan tingkat signifikansi 0,000. Dengan menggunakan batas signifikansi 0,05 , maka diperoleh nilai t tabel dengan $\mathrm{df}=33$ adalah sebesar 1,6924. Dengan demikian diperoleh $t$ hitung $(5,058)>$ t tabel (1,6924), sehingga $\mathrm{Ha}$ diterima. Kesimpulannya hipotesis yang menyatakan bahwa metode kerja berpengaruh positif dan 
signifikan terhadap kinerja graving dock adalah terbukti. Hasil ini sama dengan penelitian dari Koenig and Baba (2003) bahwa lingkungan kerja yang memadai berperan dalam peningkatan produkvitas galangan. Roland, F. et al (2004) menyatakan bahwa teknik kerja mempunyai pengaruh signifikan terhadap performa produk kapal dan kualitas yang dihasilkan. Lamb, T., et al (2006) menyatakan bahwa peningkatan proses kerja akan meningkatkan produktivitas. König et al (2007) menyatakan bahwa langkah kerja yang tepat sangat penting dilakukan karena mempengaruhi secara langsung keberhasilan dan kecepatan proyek.

\section{KESIMPULAN DAN SARAN}

\section{Kesimpulan}

Berdasarkan hasil analisis tersebut, maka kesimpulan yang didapat dari penelitian ini adalah :

1. Pengujian pada variabel produktivitas tenaga kerja menghasilkan tingkat signifikansi 0,000 dan nilai $\mathrm{t}$ hitung $=$ $6,316>\mathrm{t}$ tabel $(1,6924)$. Hasil penelitian menunjukkan produktivitas tenaga kerja mempunyai pengaruh positif dan signifikan yang mengindikasikan bahwa peningkatan produktivitas tenaga kerja akan meningkatkan kinerja graving dock. Nilai koefisien regresi sebesar 0,256 atau 25,6 \% menunjukkan bahwa penambahan jam kerja/lembur yang setara dengan sehari/24 jam dapat meningkatkan jumlah kapal yang masuk graving dock sebesar
125,6\% menjadi 76 kapal/tahun dari kondisi saat ini yang 63 buah kapal/tahun.

2. Uji hipotesis membuktikan variabel metode kerja memperoleh tingkat signifikansi 0,000 dengan nilai t hitung $=$ $5,058>\mathrm{t}$ tabel $(1,6924)$. Hal ini berarti bahwa perbaikan metode kerja di graving dock PT. JMI dapat meningkatkan kinerja graving dock sebesar $24,9 \%$.

3. Hasil uji $F$ menghasilkan nilai $F$ hitung $(217,555)$ lebih besar dari nilai $F$ tabel $(3,2759)$, membuktikan bahwa variabel produktivitas tenaga kerja dan teknik kerja secara bersama-sama mempunyai pengaruh yang positif dan signifikan terhadap kinerja graving dock di PT. JMI Semarang.

\section{Saran}

Berdasarkan hasil penelitian ini, maka PT Janata Marina Indah perlu mengagendakan beberapa kebijakan, antara lain :

1. Dalam hal peningkatan produktivitas pekerja agar semakin kompeten dan berdaya saing maka perlu diberikan pelatihan, training, ketrampilan, dan motivasi pada tenaga kerja dari STM, D3, S1 sesuai dengan bidangnya kerja masing-masing, memberikan tunjangan uang transport, bonus atau THR, memberikan premi mingguan bagi pelaksana konstruksi graving dock yang rajin atau tidak pernah mangkir dalam bekerja.

2. Dalam hal metode kerja, kebijakan yang perlu diambil adalah memberikan metode 
kerja yang dapat dengan mudah dimengerti tiap pelaksana konstruksi graving dock dan dilaksanakan dengan cepat, dengan hasil yang baik dan efesien serta menggunakan metode kerja yang sesuai dengan kondisi lingkungan dan peralatan yang tersedia.

3. Lingkup penelitian ini hanya di PT.Janata Marina Indah Semarang, agar diperoleh analisis yang lebih luas cakupannya, maka penelitian mendatang disarankan untuk meneliti pada beberapa perusahaan sejenis.

4. Objek penelitian berfokus pada Graving dock, untuk penelitian mendatang disarankan dapat mengambil penelitian perbandingan kinerja pada sarana reparasi baik berupa Floating Dock, Helling maupun Sincrolift.

\section{DAFTAR PUSTAKA}

Amrozi, Ahmad Hari. 2007. Faktor Faktor Yang Mempengaruhi Kinerja Pemeliharan Jembatan. Tesis Magister Teknik Sipil Unissula Semarang.

Aslesen, Sigmund, and Svein Erik Moen. (2012). Communication in the Manufacturing Industry : An Empirical Study of the Management of Engineering Drawing in a Shipyard International Journal of Productivity Management and Assessment Technologies (IJPMAT) 1 (4) 2240.
Bertram, V. (2003). Strategic control of productivity and other competitiveness parameters Proceedings of the Institution of Mechanical Engineers, Part M: Journal of Engineering for the Maritime Environment, 217(2), 6170.

Biro Klasifikasi Indonesia.(2003) Register 2003. Jakarta

Bruce, G. J. (2006). A Review Of The Use Of Compensated Gross Tonnes For Shipbuilding Performance Measurement. Journal of Ship Production, 22(2), 99-104.

Caridis, Piero. (2001). Inspection, Repair and Maintenance Ship Structures Part B. London : Witherby Publishers.

Farhum, St. Aisyah. (2010). Kajian Stabilitas Empat Tipe Kasko Kapal Pole and Line. Jurnal Ilmu dan Teknologi Kelautan Tropis, 02 (02), 53-61.

First Marine International. (2005). Findings For The Global Shilbuilding Industrial Base Benchmarking Study. Report of Secretary of Defense United States of America.

Gebhardt, L. P., \& Jarvis, R. G. (2003). Productivity Improvement at the SENESCO Shipyard. Journal of Ship Production, 19(3), 187-193.

Ghozali, Imam. (2006). Aplikasi Analisis 
Multi Variate dengan Program SPSS, Semarang: BP-UNDIP

Hasan, M. Iqbal. (2002). Pokok-pokok Materi Metodologi Penelitian dan Aplikasinya. Jakarta: Ghalia Indonesia.

House, David John. (2003). Dry Docking and ShipBoard Maintenance. London: Whitherby Publishers.

Huda, Miftahul. (2006). Keseimbangan Gaya Hidrostatis Uplift dan Beban Kontra Sebagai Pengganti Tiang Pancang Pada Bangunan Graving dock. Jurnal Aksial, 08 (02), 68-75.

Koenig, P. C., Narita, H., \& Baba, K. (2003). Shipbuilding productivity rates of change in East Asia. Journal of ship production, 19(1), 32-37.

König, M., Beißert, U., Steinhauer, D., \& Bargstädt, H. J. (2007, September). Constraint-based Simulation of Outfitting Processes In Shipbuilding And Civil Engineering. In Proceedings of the 6th EUROSIM Congress on Modeling and Simulation.

Krishnan, S. Navaneetha. (2012) A Scientific Approach to Measure Shipbuilding

Productivity. Maritime Affairs: Journal of the National Maritime Foundation of India 8.(1) 136-149.

Lamb, T., Gray, W., Colton, T., Comer, J., \& Cahill, P. D. (2001). World-class Shipbuilders: Their Productivity
Using Lean-Manufacturing Principles. Discussion. Author's Closure. Transactions-Society of Naval Architects and Marine Engineers, 109, 285-308. ., \& Hellesoy, A. (2002). A shipbuilding Productivity Predictor. Journal of Ship Production, 18(2), 79-85. ., Chung, H., Spicknall, M., Shin, J. G., Woo, J. H., \& Koenig, P. (2006). Simulation-based Performance Improvement For Shipbuilding Processes. Journal of Ship Production, 22(2), 49-65.

Lee, D. K., Shin, J. G., Kim, Y., \& Jeong, Y. K. (2014). Simulation-Based Work Plan Verification in Shipyards. Journal of Ship Production and Design.

Moyst, H., \& Das, B. (2005). Factors Affecting Ship Design And Construction Lead Time And Cost. Journal of Ship Production, 21(3), 186-194.

Pires Jr, F. C., \& Lamb, T. (2008). Establishing performance targets for shipbuilding policies. Maritime Policy \& Management, 35(5), 491502.

Reksohadiprodjo, Sukanto dan Indriyo Gitosudarmo. (2000). Manajemen Produksi Edisi 4. Jogjakarta: BPFE UGM.

Roland, F., Manzon, L., Kujala, P., Brede, M., \& Weitzenbock, J. (2004). 
Jurnal Teknik Sipil Unaya

Advanced joining techniques in

European shipbuilding. Journal of

Ship Production, 20(3), 200-210.

Shin, J. G., \& Sohn, S. J. (2000).

Simulation-based Evaluation of

Productivity For The Design Of An

Automated Fabrication Workshop

In Shipbuilding. Journal of Ship

Production, 16(1), 46-59.

Soegiono dkk. (1984). Kamus Istilah

Teknik Kapal edisi II. FTK ITS

Surabaya.

Soejitno. (1999). Teknik Reparasi Kapal.

Jurusan Teknik Perkapalan ITS

Surabaya.

Sugiyono. (2005). Statistik Untuk

Penelitian, Bandung : Alva Beta. 